\title{
Adapting the Dyna-CLUE model for simulating land use and land cover change in the Western Cape Province
}

\author{
Petronella Tizora ${ }^{1}$, Alize le Roux ${ }^{2}$, Gerbrand Mans ${ }^{2}$ \& Antony K Cooper ${ }^{1,2}$ \\ ${ }^{1}$ Centre for Geoinformation Science, University of Pretoria, Pretoria, South Africa, \\ pettychiwi@gmail.com \\ ${ }^{2}$ CSIR, Pretoria, South Africa, aleroux1@csir.co.za, gmans@csir.co.za, acooper@csir.co.za
}

\section{DOI: http://dx.doi.org/10.4314/sajg.v7i2.7}

\begin{abstract}
Models which integrate and evaluate diverse factors of Land Use and Land Cover (LULC) change can be used to guide planners in making more informed decisions and achieving a balance between urban growth and preservation of the natural environment. The implementation of these models at a provincial scale is however very limited in South Africa. LULC change models are valuable if their structures are based on a deep knowledge of the system under investigation and if they produce credible results. This study therefore investigates the suitability of LULC change models in simulating LULC changes at a provincial scale in a South African context. The DynaCLUE model was implemented using the following as inputs: spatial policies and restrictions; landuse type conversions; land use requirements (demands) and location characteristics. The model produced probability maps and simulation maps for the years between 1990 and 2014. Validation of the simulated maps was conducted using both visual and statistical analysis and the results indicated that the simulated maps were in good agreement with the validation map. This study contributes to the implementation of LULC change models at a provincial scale in a South African context. Knowledge derived from this study can be used by planners as a guide to effectively gauge the impacts that planning policies and other driving factors might have on future LULC patterns in the Western Cape Province.
\end{abstract}

\section{Introduction}

Models which integrate and evaluate diverse factors of Land Use and Land Cover (LULC) change can be used to guide planners in making more informed decisions and achieving a balance between urban growth and preservation of the natural environment. A diverse array of LULC change models has been developed, implemented globally and recommended as important in making land use decisions, yet the implementation of such models is limited in South Africa. This poses a challenge to regions such as the Western Cape Province where, similar to other growing provinces in developing countries, there is evidence of rapid and unplanned development in environmentally sensitive areas and policies are being implemented without estimation of the impacts of changes in land use (Tizora et al., 2016). 
Various categories or classifications of LULC change models have been identified by different researchers. The diversity of these categories is due to differences in scientific disciplines, model objectives, modelling techniques, theoretical backgrounds, research questions and scales of application. The two main structures of models identified in literature are top-down and bottom-up models. Top down-models originate from landscape ecology, are pattern oriented and based on remote sensing data (Castella and Verburg, 2007). These models are used when aggregate rates of land use change can be determined for the region as a whole through statistical or mathematical formulation (Verburg, 2006). In contrast, bottom-up models describe actors of land use change and their interaction with the environment. Actors are in the form of individuals and institutions such as farmers, land owners, communities, government bodies and property management agencies. Bottom-up models are often referred to as agent-based models (Castella and Verburg, 2007), which consist of agents as autonomous decision making entities; an environment wherein agents interact; rules defining the interaction between agents and the environment; and rules determining the sequence of actions in the model (Parker et al., 2002).

According to Verburg (2006), selection of either a top-down or bottom up modelling approach depends on the extent of analysis and the dominating land use change processes operating in the area under investigation. Top-down approaches are adequate when land use changes are influenced by regional factors whilst bottom-up approaches are sufficient when land use changes are steered by local processes. Top-down models mostly make use of remote sensing and census data as main inputs. Examples of top-down models are CLUE (Veldkamp and Fresco, 1996), CLUE-s (Verburg et al., 2002), Environment Explorer (White and Engelen, 2000), DINAMICA (Soares-Filho et al., 2002) and CA_Markov (Eastman, 2012). On the other hand, bottom-up models require extensive field-work to collect information on agents' behaviour and formulate rules which determine interaction with the environment. A popular bottom-up model that incorporates local drivers of land use change is the SLEUTH model. Whilst there are various models that exclusively implement topdown or bottom-up approaches, some models combine these approaches to create hybrid models. An example is Dyna-CLUE, a hybrid model developed by Verburg and Overmars (2009).

An extensive review of academic literature has revealed that no attempts have been made to implement LULC change models at a provincial level in South Africa. LULC changes operating at provincial levels have significant impacts on regional scale issues such as climate change and food security. Furthermore, processes which contribute to LULC change do not operate in isolation: various factors operate at different scales and there is need to analyze higher level processes which influence LULC change. This study will therefore fill the gap of LULC change models at a provincial scale in a South African context. The aim of this study is to investigate the suitability of Dyna-CLUE model in simulating LULC changes and supporting planning at a provincial scale in South Africa. 


\section{Study area \& drivers of LULC change}

\subsection{Study area}

The study was conducted in the Western Cape Province, the fourth largest province in South Africa, covering 10.6\% (129 462 square kilometres) of the country's total land surface (Maree and Van Weele, 2013). Approximately $11.3 \%$ of South Africa's total population currently resides in the Western Cape and migration into the region from other provinces and countries is expected to continue (Stats SA, 2014). The Province consists of five district municipalities (Cape Winelands, West Coast, Central Karoo, Eden and Overberg) and one metropolitan municipality (City of Cape Town).

\subsection{Drivers of LULC change}

Changes in LULC are determined by how individual landowners, communities and governments control land use and make decisions on how to use land. Such decisions are influenced by the interactions between socioeconomic factors, such as population, and biophysical factors which vary at different scales (Lambin and Geist, 2007). Briassoulis (2000) confirms this and further clarifies that biophysical drivers do not have a direct impact on land use change but impact on land cover change, which in turn influences the decisions of land managers.

LULC change can therefore be modelled as a function of socio-economic and biophysical factors. These factors are often referred to as 'driving factors'. The driving factors of LULC change are categorized as either proximate or underlying, where the former are direct modifications by individuals at a local scale, such as individual farms, and the latter are indirect changes which occur at a regional scale (Lambin and Geist, 2007). Proximate driving factors are caused by human activities such as infrastructure and agriculture expansion, whereas underlying factors are caused by complex interactions between social, political, demographic and biophysical variables (Lambin et al., 2001). Lambin et al. (2001) further maintain that proximate causes can be categorized into the three broad categories of agricultural expansion, wood extraction and infrastructure expansion. Briassoulis (2000) describes underlying driving forces as socio-economic drivers which comprise of demographic, economic, institutional factors, technological and cultural or socio-political. 


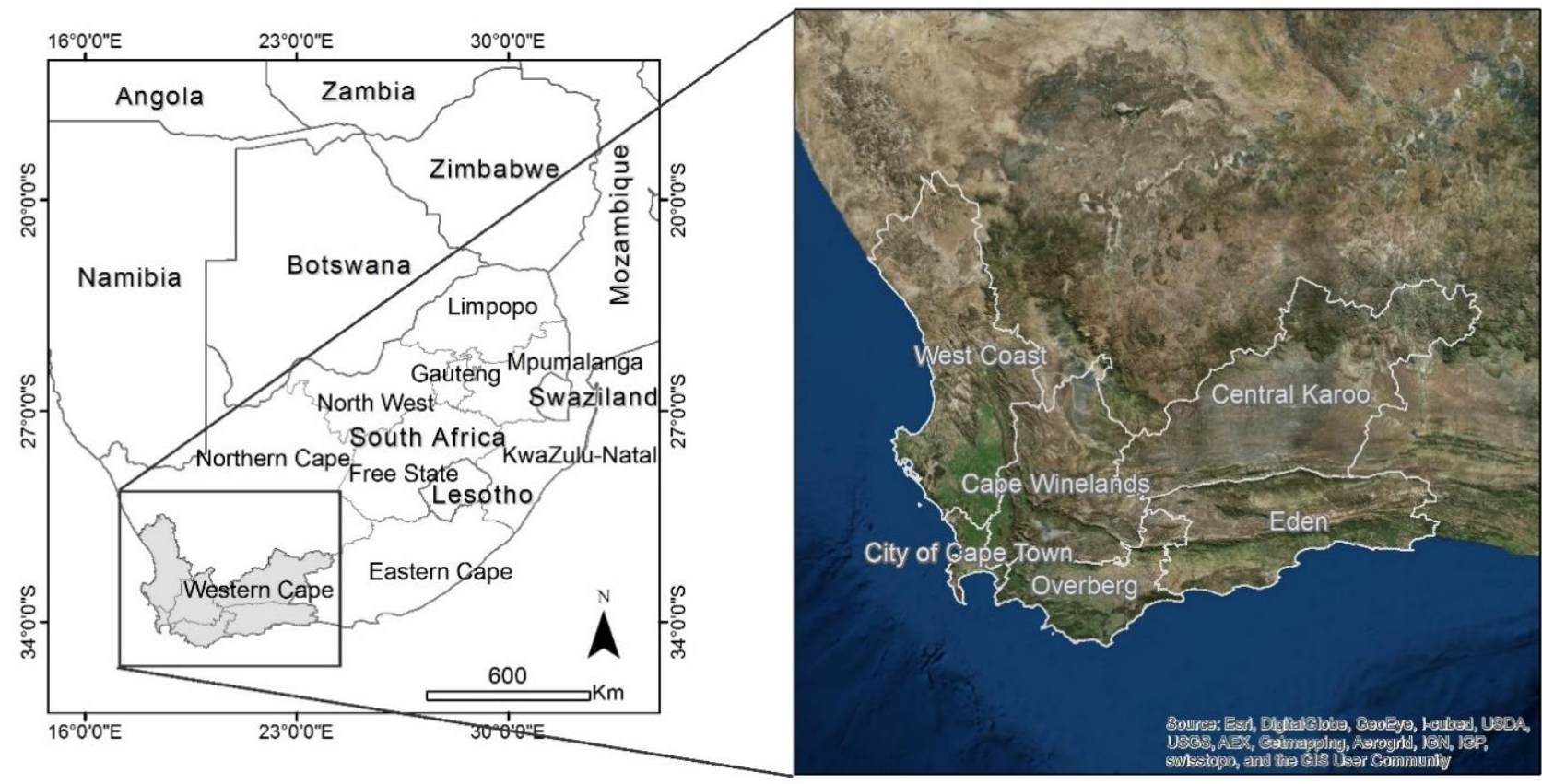

Figure 1. Geographical location of the Western Cape Province

As ascertained above, international researchers have identified broad categories of drivers of LULC change. However, these drivers vary depending on the context of the area under study and the scale of analysis. South African academic references on drivers of LULC change are limited, therefore a prior investigation on drivers of LULC changes in the study area was conducted by Tizora et al. (2016). The findings from the study indicated that changes LULC in the Western Cape Province are a result of diverse interrelated factors that operate at different scales. At a provincial scale, changes emerge from political factors through legislation and policies aimed at poverty alleviation, promoting access to basic services, reducing inequalities and promoting economic growth. Patterns of LULC changes are consistent with nodes of economic growth which occur in the Cape Metropolitan, Eden and West Coast District Municipalities. The agriculture, tourism and industry sectors in these municipalities attract foreign investments leading to net in-migration from other provinces. Migration coupled with natural increase results in population growth which increases the amount and intensity of pressure exerted on resources and consequently changes the state of land (Tizora et al., 2016).

\section{Approach \& methodology}

The Dyna-CLUE model (Verburg and Overmars, 2009) was used to simulate LULC changes during the period 1990 to 2014. Dyna-CLUE is an adapted CLUE-s model by Castella and Verburg (2007) and Verburg et al., (2003), based on demand allocation for different land use classes into individual grid cells. This model has been implemented in multiple case studies in different regions and countries including a study by Le Roux \& Augustijn (2015) to quantify spatial implications of future land use policies in the City of Johannesburg. The Dyna-CLUE model requires the following 
as inputs: spatial policies and restrictions, land-use type conversions, land use requirements (demands) and location characteristics. Spatial policies indicate areas where land use changes are restricted by policies. These policies must be in the form of maps showing areas where the policies will be implemented e.g. national parks.

Land-use type conversion settings are temporal simulation dynamics that indicate possible and impossible conversions amongst land use categories. Conversion settings are in the form of conversion elasticities and transition matrices, where the former are concerned with reversibility of land use change and the latter are probabilities of transitions between land uses. Land use requirements are calculated at aggregate level using by extrapolation of trends of land use change of the recent past into the near future (Verburg, 2010). Location characteristics are concerned with the expectations of land use changes to occur at places that have specific characteristics i.e. locations with the highest preference.

An overview of the model that was adapted for simulation of LULC changes in the South African context is illustrated in Figure 2. This is followed by sections which describe the different input components of the model, data preparation, population of the model and allocation procedure.

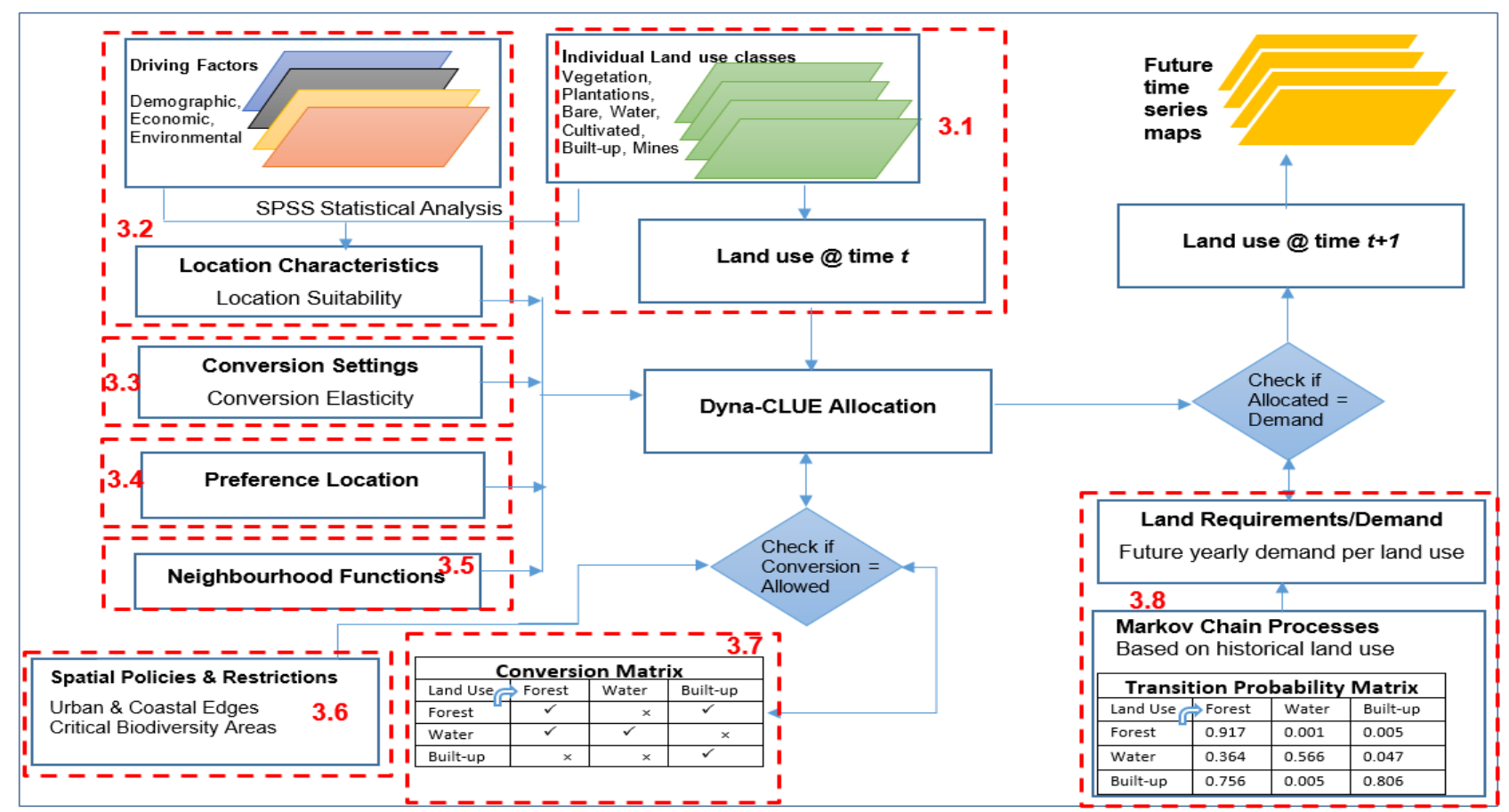

Figure 2. Dyna-CLUE modelling framework for the Western Cape Province [adapted from Verburg and Overmars (2009), and Le Roux and Augustijn (2015)]

\subsection{LULC Data}

LULC data used in the study area were based on LULC datasets of 1990 and 2013/14 obtained from the Department of Environmental Affairs (DEA). These datasets cover the whole country at a 30m spatial resolution and are known as the 1990 South African National Land Cover Dataset (35 
Classes) and the 2013/2014 South African National Land Cover Dataset (72 Classes). These datasets were created by GEOTERRAIMAGE (GTI) and incorporate both land-cover and land-use data which are referred to as "Land-Cover". The 1990 dataset was derived from multi-seasonal Landsat 5 imagery acquired between 1989 and 1991, while the 2013/14 dataset was generated from Landsat 8 imagery acquired in 2013 and 2014 (GEOTERRAIMAGE, 2014). The 1990 LULC map was used as the base map and the 2013/14 LULC map was used to validate the results predicted by the model.

\subsection{Location characteristics}

Location characteristics are determined by location preference of a land use, calculated through logistic regression models which indicate the preference of a specific land use based on quantification of its relationship or correlation with explanatory factors. The explanatory variables used were based on drivers of LULC change in the study area. Based on a survey conducted with local town and regional planners who work at various level within the Western Cape Government the following driving factors were included in the modelling exercise: population, distance to economic nodes, distance to agricultural activities, distance to agri-tourism and land capability (Tizora et al., 2016). Other relevant factors were not included due to a lack of data availability.

Table 1 indicated the reslts of the stepwise regression results. Logistic regression is a common method in calculating the coefficients ( $\beta$-values) of the logistic (logit) model, which are used to find the probability of a certain cell being allocated a land use type, given a set of driving factors (Verburg et al., 2002). Stepwise regression was therefore used to select the relevant driving factors and those variables with no significant influence on land use patterns were excluded from the final regression equation. The ROC (Receiver operating characteristic) values below indicate the goodness of fit of the logistic regression model. The closer the ROC value to 1 the better the fit of the logistic regression model; the closer the value to 0.5 the more random the occurrences of a specific land use type are. The ROC values presented below indicates the logistic regression model performance and the values derived in this case study. The ROC values show that the model is generally acceptable, with most values being above 0.8 . Cultivated land-use has a ROC of 0.64 ; this value needs to be improved in future by incorporating more accurate driving factors which have a stronger correlation with the land-use. 
Table 1. Stepwise regression results

\begin{tabular}{|c|c|c|c|c|}
\hline \multirow{2}{*}{ Land use type } & $\begin{array}{c}\text { (1) } \\
\text { Plantations }\end{array}$ & $\begin{array}{c}\text { (3) } \\
\text { Bare }\end{array}$ & $\begin{array}{c}\text { (4) } \\
\text { Cultivated }\end{array}$ & \multicolumn{2}{|c|}{\begin{tabular}{c} 
(5) Built- \\
\cline { 2 - 5 }
\end{tabular}} & $\beta$-values & $\begin{array}{c}\beta- \\
\text { values }\end{array}$ & $\beta$-values & $\beta$-values \\
\hline (0) Agri-Processing & - & - & 0.00015 & 0.0001 \\
\hline (1) Economic Nodes & 0.0001 & 0.0001 & - & - \\
\hline (2) Population & - & - & - & 0.0016 \\
\hline (3) Land Capability & - & - & 0.0001 & - \\
\hline ROC Values & 0.864 & 0.817 & 0.644 & 0.92 \\
\hline
\end{tabular}

\subsection{Conversion settings}

Conversion elasticity gives an indication of conversion costs from one land use type to another and is assigned a value between 0 and 1 . A high elasticity value (close to 1 ) indicates a high cost of conversion and a consequently higher probability of the existing land use type remaining at that location (Verburg and Overmars, 2009). Determining the conversion elasticities for implementing the Dyna-CLUE model in the study area was based on analysis of historical land use data and expert knowledge. High conversion elasticity values were assigned to built-up and water land use types, given their low probabilities of being converted to other land use types, whereas low conversion elasticity values were allocated to vegetation and bare land due to their higher likelihood of conversion to other land use types. Vegetation, plantations and bare land uses were assigned low conversion elasticity of 0.1 since they are unstable and can easily be converted to another class. Cultivated land use was assigned a conversion elasticity of 0.4 , which is higher than the previously mentioned classes since cultivation requires a higher investment and is thus more stable. Mining was allocated a conversion elasticity of 0.6 because it requires a greater investment than cultivated land use class and is therefore more stable. The final conversion settings are implemented in the model as part of the change potential formula explained under section 3.8 as $\left(\right.$ Elas $\left._{i, t, l u}\right)$.

\subsection{Preference location}

Land use types can have location-specific preferences due to spatial policies or research initiatives which can be implemented through Spatial Development Frameworks (SDFs) and municipality plans. In the case of the Western Cape Province, the mining land use was assigned location preferences based on mining potential data created by the South African National Biodiversity Institute (SANBI). SANBI (2005) determined mining potential at a national level based on the accuracy of deposit mapping, its size and commodity types. The attributes of this dataset consist of mining potential of areas ranging from 0 (low potential) to 100 (high potential). 
Mining potential was included in the model by increasing the probability of mining land use in locations with a high potential for mining to occur. The location-specific preference maps are implemented in the model as part of the change potential formula explained under section 3.8 as input value $\left(\right.$ Compt $\left._{t, l u}\right)$.

\subsection{Neighbourhood influence}

According to the first law of geography by Tobler (1970), "everything is related to everything else, but near things are more related than distant things". This law plays a significant role in understanding spatial interactions in LULC dynamics and forms an important component of land use change models. In land use change models, this implies that a land use transition will most likely cluster next to similar established land use types. Verburg et al. (2004a) characterised the location of a neighbourhood by defining an enrichment factor which is defined by the occurrence of a land use type in the location's neighbourhood relative to its occurrences in the whole study area. According to Verburg et al. (2004a) the enrichment factor can be defined by the equation:

$$
F_{i, k, d}=\frac{n_{k, i, d} / n_{d, i}}{N_{k} / N}
$$

Where:

$F_{i, k, d}$ is the enrichment of neighbourhood $(d)$ of location $(i)$ with land use type $(k)$;

$n_{k, i, d}$ is the number of cells of land use type $(k)$ in the neighbourhood $(d)$ of cell location $(i)$;

$n_{d, i}$ is the total number of cells in the neighbourhood;

$N_{k}$ is the number of cells with land use type $k$ in the whole raster;

$N$ is the total number of cells in the raster.

Enrichment factors were calculated for the built-up and mines land use types using the focal statistics function in ArcMap. As proposed by Verburg et al. (2004a), analysis of the explanatory influence of enrichment factors through logistic regression was performed to assess the relevance of enrichment factors.

\subsection{Spatial policies \& restrictions}

Spatial policies and restrictions are implemented by preventing the identified areas from changing to any other land use type. Restrictions that constrain developments in the Western Cape Province are implemented in response to biodiversity threats due to conversions of the natural environment to man-made landscapes. Such restrictions aim to support biodiversity and ecosystem fuctioning and are in the form of political factors, i.e legislation, policies and plans at national, provincial and local levels. Examples of national legislation are the National Environmental Management Act, No 107 of 1998, (NEMA) and the Biodiversity Act, No 10 of 2004 (NEMBA); provincial legislation includes the Western Cape Nature Conservation Board Act, No 15 of 1998, and at a municipal level, restrictions are implemented in SDFs. Two restriction layers were used in the Western Cape Province model to show the impact of two different scenarios. The first scenario 
permits land use conversions throughout the province, as an AS-IS scenario: this scenario was created from the initial 1990 base map by reclassification of all the land use classes and assigning them with code 0 to show that all convesions are allowed. The second scenario is a Policy-Led scenario where the restriction file excludes national parks from conversions.

\subsection{Conversion matrix}

Dyna-CLUE specifies land use type conversion settings in a conversion matrix. The purpose of the conversion matrix is to:

- Define to what other land use types the initial land use is permitted to be converted.

- Indicate the number of years a land use type at a specific location should remain unchanged before conversion to another land use type is allowed.

The conversion matrix used in the Western Cape Province was determined using previous trends, i.e. analysis of changes between 1990 \& 2014 using land change modeler for ArcMap (Tizora et al., 2016). The results of the analysis are illustrated in Table 2, where "1" represents possible conversions and "0" shows impossible conversions. The table also shows that changes in plantations are only recognised from the $12^{\text {th }}$ year (year 2002) since this was the year when the forest exit policy was implemented and major changes in plantations began.

Table 2. Conversion Matrix

\begin{tabular}{|l|r|r|r|r|r|r|r|}
\hline & Vegetation & Plantations & Water & Bare & Cultivated & Built-Up & \multicolumn{1}{c|}{ Mines } \\
\hline Vegetation & 1 & 0 & 0 & 0 & 1 & 1 & 1 \\
\hline Plantations & 112 & 1 & 0 & 0 & 112 & 112 & 112 \\
\hline Water & 1 & 0 & 1 & 0 & 1 & 0 & 0 \\
\hline Bare & 1 & 0 & 0 & 1 & 1 & 1 & 1 \\
\hline Cultivated & 0 & 0 & 0 & 1 & 1 & 1 & 1 \\
\hline Built-Up & 0 & 0 & 0 & 0 & 0 & 1 & 0 \\
\hline Mines & 0 & 0 & 0 & 0 & 0 & 0 & 1 \\
\hline
\end{tabular}

\subsection{Land use requirements}

Land use demands between 1990 and 2014 were calculated using linear interpolation. These requirements, together with the inputs explained in the sections above were used to run DynaCLUE and land use was allocated based on the equation by Verburg et al. (2004a):

$$
\text { Ptot }_{i, t, l u}=\text { Ploc }_{i, t, l u}+\text { Ploc }_{i, t, l u}+\text { Elas }_{i, t, l u}+\text { Comp }_{t, l u}
$$


Where:

Ptot $_{i, t, l u}=$ the highest total probability calculated for every land use $(l u)$ for every grid cell or location $(i)$ at time $(t)$ by summation of:

Ploc $_{i, t, l u}$ - Location suitability

$P n b h_{i, t, l u}$ - Neighbourhood functions

Elas $_{i, t, l u^{-}}$Conversion settings

Comp $_{t, l u}$ - Preference location

\section{Model outputs \& performance}

The Western Cape Dyna-CLUE model was run by selecting a scenario and demand file for that scenario. Each scenario generated 23 simulation maps for the years 1991 to 2014. The simulated maps were validated against observed land use change maps to find out how the model performed and hence reveal the accuracy of predicted maps. Due to unavailability of readily comparable LULC data at a provincial scale, the map used for validation was the 2013/2014 LULC map. Validation of the simulated map was performed using both visual and statistical approaches, as endorsed by Pontius and Chen (2006).

\subsection{Visual validation}

The visual validation approach was conducted to quickly analyse spatial patterns which could otherwise be undetectable through statistical methods. The importance of visual map inspection is that it reveals some characteristics of maps that may be overlooked by directly performing statistical analysis on simulated maps (Visser, 2004). Based on this notion, visual analysis was performed between two sets of maps, that is, the initial 1990 LULC map and the 2013/2014 reference map and the 1990 LULC map with the simulated 2014 map.

Visual analysis was done using IDRISI crosstabulation with hard classification analysis. Hard classification analysis is used when pixels in maps belong to exactly one category without any partial membership to more than one category. The outputs of hard classification crosstabulation analysis of the two sets of maps were cross classification images which consisted of pixels that showed a combination of categories of the maps being compared. These images allowed visualisation of changes that occurred between each LULC category and every other LULC category. To simplify the visualisation analysis results, the output cross classification image from analysis of the 1990 LULC map and the 2013/14 LULC reference map was reclassified in ArcMap to show pixels where changes occurred and where there were no changes (top right of Figure 4). Similarly, the image at the bottom right of Figure 4 gives an indication of changes that occurred between the 1990 initial map and the 2014 AS-IS scenario simulated map. 


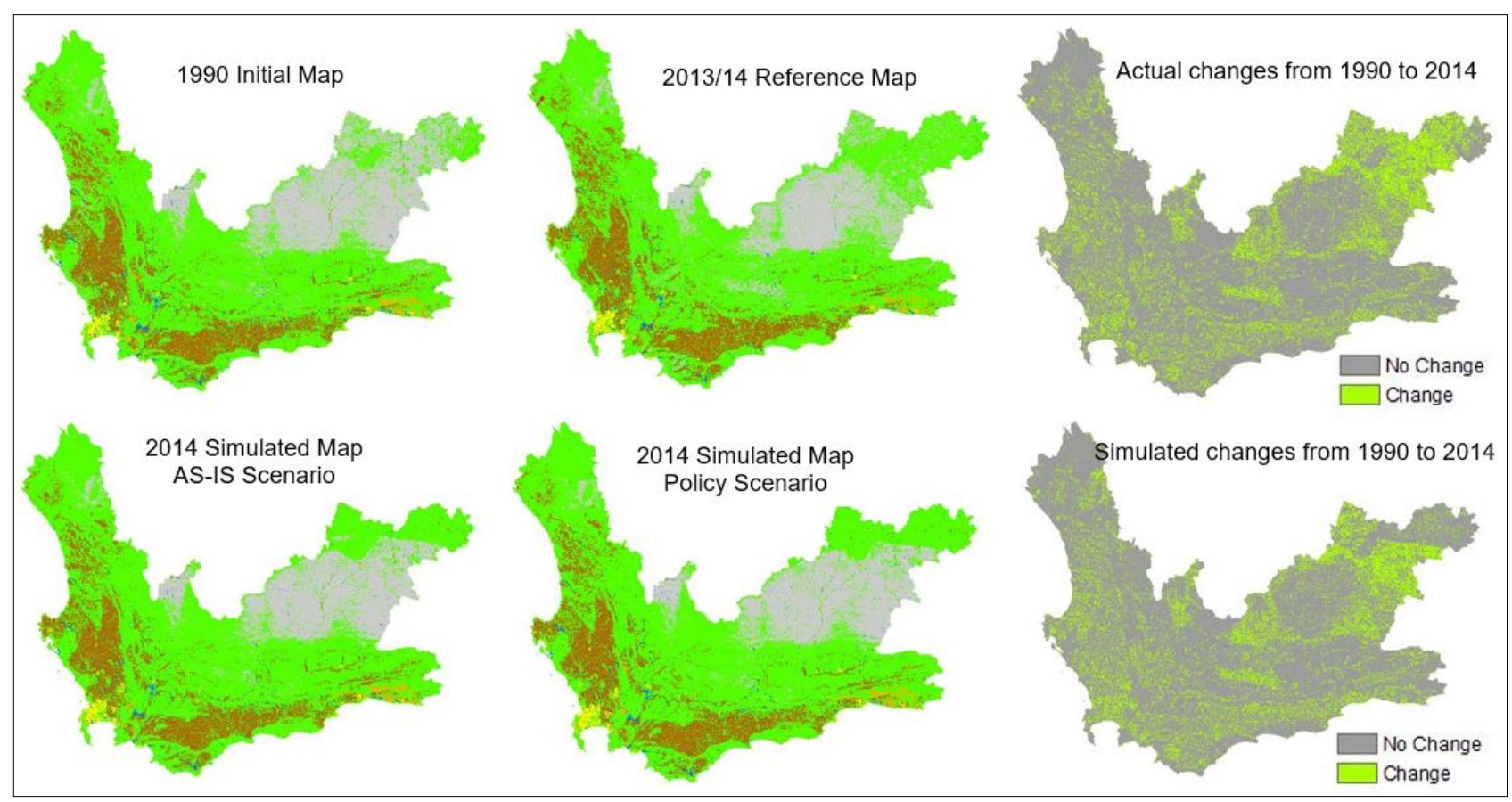

Figure 4: Visual analysis of the initial 1990 map, 2014 reference map and 2014 simulated maps

\subsection{Statistical validation}

The second approach conducted in validation of the simulated map was the statistical approach. The purpose of statistical validation was to find out how well the 2013/2014 reference map agreed with the 2014 simulated map in terms of both quantity and location of cells in each category. The issues of quantity and location agreement in statistical validation of the Western Cape Dyna-CLUE model were addressed using the VALIDATE module in IDRISI. The VALIDATE module in IDRISI was therefore run for the entire study area with the 2013/14 LULC map as the reference map and the 2014 predicted LULC map as the simulated map. Outputs of the VALIDATE results were kappa statistics and components of agreement and disagreement which are explained in the following sections.

\subsubsection{Kappa statistics}

Kappa statistics of 0 indicate an agreement due to chance and of 1 a perfect agreement. The accuracies of the Western Cape model were $\mathrm{K}_{\mathrm{no}}=0.9001, \mathrm{~K}_{\text {standard }}=0.08528$ and $\mathrm{K}_{\text {location }}=0.8623$, indicating that the model is acceptable for future predictions. However, after working with Kappa indices for over a decade, Pontius Jr and Millones (2011) discourage the use of the indices in model validation describing them as "useless, misleading, and/or flawed". Despite the wide application of Kappa indices by researchers in LULC change and remote sensing applications, this study follows the recommendations made by Pontius Jr and Millones (2011), disregards Kappa statistics and focuses on components of agreements and disagreements as the main statistical validation techniques. 


\subsubsection{Components of agreement \& disagreement}

Based on the VALIDATE results, the disagreement due to quantity was 0.0065 , which is close to 0 . This value indicates the amount of disagreement associated with the 2014 simulated map failing to quantify each LULC category correctly. The disagreement at grid cell level was 0.0809. Grid level disagreement is the error associated with the 2014 simulated map failing to specify perfectly the correct locations of LULC categories. Strata disagreement was 0, which is logical since there was no strata image defined to include analysis by region. The overall disagreement was calculated by summation of quantity disagreement, grid level disagreement and strata disagreement, producing a total disagreement of 0.0874 .

The VALIDATE module also calculated components of agreements which describe characteristics of agreement between the simulated 2014 map and the reference map. The agreement due to chance was 0.1250 . This agreement is achieved with no information on location or quantity and was used as the baseline to compare actual agreements. The agreement due to quantity was 0.2808 and this value is the additional agreement that the 2014 simulated map was accurate in terms of specifying the quantity of each LULC category. The agreement due to grid cell level location was 0.5068 and gives an indication of additional agreement that the 2014 simulated map was somewhat accurate in specification of grid cell level location of each LULC category. The overall agreement was calculated by adding agreement due to chance with agreement due to quantity and agreement due to grid cell level location. The overall agreement between the 2013/14 reference map and the 2014 simulated map was 0.9126 , which indicates a good simulation fit.

Based on both the statistical and visual validation results it was concluded that the simulation maps produced by Dyna-CLUE were in good agreement with the reference maps. This proves that the model is acceptable and can be used to predict future LULC patterns in the study area and hence guide planners to effectively gauge the impacts that planning policies and other driving factors might have on future LULC patterns in the Western Cape Province.

\section{Conclusions \& recommendations}

The purpose of this study was to investigate the suitability of the Dyna-CLUE land use model in simulating LULC changes and supporting planning at a provincial scale in South Africa. This was achieved by implementing the Dyna-CLUE model which made use of spatial policies and restrictions; land-use type specific conversions; land use requirements (demands) and location characteristics as inputs. Spatial policies which indicate areas where land use changes are restricted by policies were included in the model in the form of a restriction map which excluded national parks from conversions. A conversion matrix which defined land use types which the initial land use is permitted to be converted to was determined using analysis of previous trends. Land use requirements or demands were calculated using linear interpolation and location characteristics which show preferences of land use were calculated through logistic regression models. 
Model validation was performed using both visual and statistical analysis. Visual analysis was performed between two sets of maps, that is, the initial 1990 LULC map and the 2013/2014 reference map and the 1990 LULC map with the simulated 2014 map. The analysis was conducted in IDRISI through crosstabulation and hard classification analysis which resulted in cross classification images which consisted of pixels that showed a combination of categories of the maps being compared. These images allowed visualisation of changes that occurred between each LULC category and every other LULC category/class.

The output cross-classification images from the analysis were reclassified in ArcMap to show pixels where changes occurred and where there were no changes. The maps of actual LULC changes and simulated changes exhibit some similarities in changes in LULC throughout the province, though there are a few differences. Statistical validation was performed to find out how well the 2013/2014 reference map agreed with the 2014 simulated map in terms of both quantity and location of cells in each category. The overall agreement between the 2013/14 reference map and the 2014 simulated map was 0.9126, which indicates a good simulation fit. The validation results indicated that the Dyna-CLUE model can simulate LULC changes in the study area effectively. The model can therefore be used to support future land use planning by incorporating policies which influence future land use, e.g. The Western Cape Urban and Coastal Edge Policy. Further improvements to the model can also be made by using land use plans as inputs to enhance simulation results.

\section{References}

Briassoulis, H. 2000. Analysis of land use change: Theoretical and modeling approaches. Web Book of Regional Science, Regional Research Institute, West Virginia University [Online]. Available: http://www.rri.wvu.edu/WebBook/Briassoulis/contents.htm [Accessed 20 January 2015].

Castella, J.-C. \& Verburg, P. H. 2007. Combination of process-oriented and pattern-oriented models of landuse change in a mountain area of Vietnam. Ecological modelling, 202, 410-420.

Eastman, J. 2012. IDRISI Selva Tutorial. Idrisi Production, Clark Labs-Clark University. Available: https://clarklabs.org/buy/.

Geist, H. J. \& Lambin, E. F. 2002. Proximate Causes and Underlying Driving Forces of Tropical Deforestation BioScience, 52, 143-150.

GEOTERRAIMAGE 2014. 2013-2014 South African National Land-Cover Dataset. Data User Report and Metadata. Available: http://www.geoterraimage.com/downloads.php [Accessed 26 July 2018].

Lambin, E. F. \& Geist, H. J. 2007. Causes of land-use and land-cover change [Online]. Available: http://www.eoearth.org/view/article/51cbed2f7896bb431f6905af [Accessed 20 January 2015].

Lambin, E. F., Turner, B. L., Geist, H. J., Agbola, S. B., Angelsen, A., Bruce, J. W., Coomes, O. T., Dirzo, R., Fischer, G. \& Folke, C. 2001. The causes of land-use and land-cover change: moving beyond the myths. Global environmental change, 11, 261-269.

Le Roux, A. \& Augustijn, E.W. 2015. Quantifying the spatial implications of future land use policies in South Africa. South African Geographical Journal 99 (1), 29-51.

Parker, D. C., Berger, T. \& Manson, S. M. Agent-based models of land-use and land-cover change. Proc. of an International Workshop, 2002. 4-7. 
Pontius Jr, R. G. \& Chen, H. 2006. GEOMOD modeling. Clark University. Available: https://www.researchgate.net/publication/239554913_GEOMOD_Modeling [Accessed 26 July 2018].

Pontius Jr, R. G. \& Millones, M. 2011. Death to Kappa: birth of quantity disagreement and allocation disagreement for accuracy assessment. International Journal of Remote Sensing, 32, 4407-4429.

Pontius Jr, R. G. \& Suedmeyer, B. 2004. Components of agreement between categorical maps at multiple resolutions. Remote sensing and GIS accuracy assessment, 233-251.

Soares-Filho, B. S., Cerqueira, G. C. \& Pennachin, C. L. 2002. DINAMICA—a stochastic cellular automata model designed to simulate the landscape dynamics in an Amazonian colonization frontier. Ecological modelling, 154, 217-235.

Tizora, P., Le Roux, A., Cooper, A. K. \& Mans, G. Land Use and Land Cover Change in the Western Cape Province: Quantification of Changes \& Understanding of Driving Factors. $7^{\text {th }}$ Planning Africa Conference 2016 - Making sense of the future: Disruption and Reinvention, 2016, Sandton Convention Centre, Johannesburg, South Africa. South Africa Planning Institute (SAPI).

Tobler, W. R. 1970. A computer movie simulating urban growth in the Detroit region. Economic geography, 46, 234-240.

Veldkamp, A. \& Fresco, L. 1996. CLUE-CR: an integrated multi-scale model to simulate land use change scenarios in Costa Rica. Ecological modelling, 91, 231-248.

Verburg, P., De Koning, G., Kok, K., Veldkamp, A. \& Priess, J. 2001. The CLUE modelling framework: an integrated model for the analysis of land use change. Land use and cover change.

Verburg, P. H. 2006. Simulating feedbacks in land use and land cover change models. Landscape Ecology, 21, 1171-1183.

Verburg, P. H. 2010. The Clue Modelling Framework. VU Amsterdam, Institute for Environmental Studies. Available: http://www.ivm.vu.nl/en/Images/Exercises_tcm234-284019.pdf [Accessed 26 July 2018].

Verburg, P. H., de Nijs, T. C., van Eck, J. R., Visser, H. \& de Jong, K. 2004a. A method to analyse neighbourhood characteristics of land use patterns. Computers, Environment and Urban Systems, 28, 667690.

Verburg, P. H., Kok, K., Pontius Jr, R. G. \& Veldkamp, A. 2006. Modeling land-use and land-cover change. Land-use and land-cover change. Springer.

Verburg, P. H. \& Overmars, K. P. 2009. Combining top-down and bottom-up dynamics in land use modeling: exploring the future of abandoned farmlands in Europe with the Dyna-CLUE model. Landscape ecology, 24, 1167-1181.

Verburg, P. H., Schot, P. P., Dijst, M. J. \& Veldkamp, A. 2004b. Land use change modelling: current practice and research priorities. GeoJournal, 61, 309-324.

Verburg, P. H., Soepboer, W., Veldkamp, A., Limpiada, R., Espaldon, V. \& Mastura, S. S. 2002. Modeling the spatial dynamics of regional land use: the CLUE-S model. Environmental management, 30, 391-405.

Verburg, P. H., Van De Steeg, J., Veldkamp, A. \& Willemen, L. 2009. From land cover change to land function dynamics: a major challenge to improve land characterization. Journal of environmental management, 90, 1327-1335.

Verburg, P. H. \& Veldkamp, A. 2004. Projecting land use transitions at forest fringes in the Philippines at two spatial scales. Landscape Ecology, 19, 77-98.

White, R. \& Engelen, G. 2000. High-resolution integrated modelling of the spatial dynamics of urban and regional systems. Computers, environment and urban systems, 24, 383-400. 